\title{
Indoor performance tests of a new type solar still - the tilted-tray, wick type solar still with a condenser room -
}

\section{新型太陽熱蒸留器の室内性能実験 一凝縮室付き傾斜トレイ・ウィック型太陽熱蒸留器一}

\author{
Fujio SUDA, Noriko MIYAMOTO and Nozomi SASAKI \\ Department of Resources and Environment Science, School of Humanities and Culture, \\ Tokai University, 1117 Kitakaname, Hiratsuka, Kanagawa 259-12 JAPAN \\ TEL:81-463-58-1211(EX.3417) FAX:81-463-50-2208 \\ ( Accepted for publication 16 November 1995 )
}

\begin{abstract}
A new type solar still $\left(85 \times 70 \times 25 \mathrm{~cm}^{3}\right)$ has been constructed, which is called as the "tilted-tray, wick type solar still with a condenser room". A new material "SOLAR- $\alpha$ " has been utilized as the wick, which was manufactured by UNITIKA LTD. Performance tests have been made under a solar simulator in the laboratory. It was found that (1) the distillation productivity linearly increases in proportion to the irradiation intensity I, (2) there is an optimum saline-water flow rate which results in the maximum productivity, and (3) its value (about $30 \mathrm{ml} / \mathrm{min}$ per $1 \mathrm{~m}^{2}$ evaporating area) is almost independent of $I$. The additional condenser room, however, has a little effect on the procuctivity, especially in the small I. Discussions have been made on the improvement of the still.
\end{abstract}

Key words: Solar Still, Distillation Productivity, Distillation Efficiency, Wick.

\section{INTRODUCTION}

本研究は著者らの提案する太陽熱膜電池1研究 の一環として行われた。すなわち、太陽熱蒸留器 を利用して海水から高温度の淡水と高濃度の塩水 を作り、太陽熱を濃度差のエネルギーとして蓄 え、それをイオン交換膜を利用した透析電池に よって電力に変換するシステム開発の一部として 行われた。

太陽熱蒸留器の動作原理は至って簡単である。 蒸留器内にガラス製のカバーを透過して入射する 太陽光によって海水を加熱・昇温し、蒸発した水 蒸気をガラスカバー内面など比較的温度の低い伝 熱面において凝縮させ、それらを収集することに より淡水を得る。従って、熱工学的には蒸発・凝 縮の相変化と湿り空気中の水蒸気成分の移動に基 づく熱・物質移動現象を利用している。太陽熱蒸 留器には、最も素朴な汲み置き式のいわゆるべイ スン型のものから、斜面に何段ものトレイを並べ た傾斜トレイ型、蒸発促進のためにウィック材を 敷きつめたウィック型、その他複雑な構造を持つ 多重効用型蒸留器などがある。2

本研究で新たに製作した太陽熱蒸留器は、傾斜 トレイ型とウィック型を兼ね備えた構造を持ち、 さらに背面部分に凝縮室を設けたものであり、
「凝縮室付き傾斜トレイ・ウィック型太陽熱蒸留 器」と呼べるものである。本研究はこの蒸留器の 性能を実験室内で種々なパラメー夕を変化させて 調べた結果である。

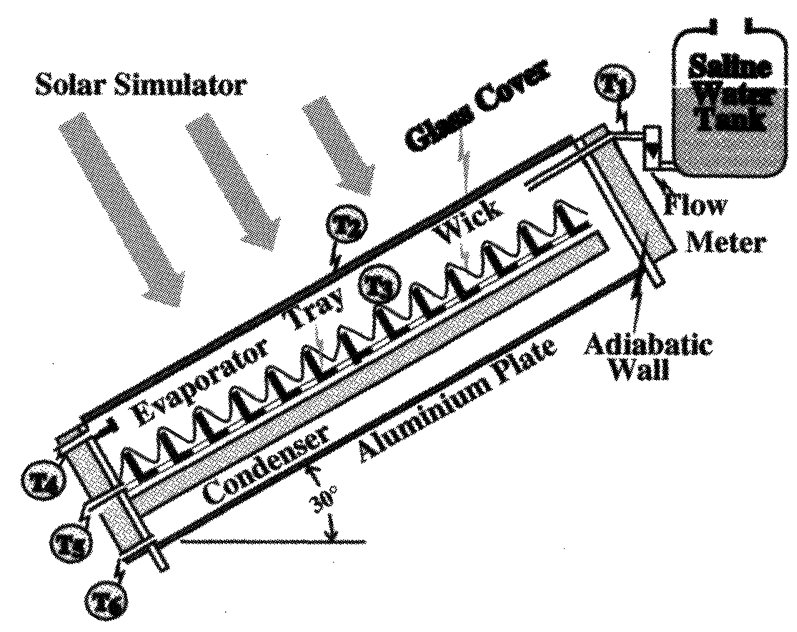

FIG,1. Cross sectional structure of the tilted-tray, wick type solar still with a condenser room. 


\section{A NEW TYPE SOLAR STILL AND ITS PERFORMANCE TESTS}

照射強度や、塩水流量などの種々なパラメー夕 に対する性能を比較して装置の最適動作条件を決 めるためには、外部条件が常に変化する屋外よ り、測定条件を任意にコントロールできる室内実 験の方が適切である。そこで、室内ソーラーシ ミュレータの下で性能を測定するための小型の装 置を製作した。断面図をFig.1に示す。これは基本 的には $11 \mathrm{~mm}$ 厚さの合板製の箱 $\left(85 \times 70 \times 25 \mathrm{~cm}^{3}\right)$ の 内側に防水塗装を施し、外側を断熱したものであ る。水平面に対して $30^{\circ}$ の傾斜をもたせてある。 上面はパッキンを介して $3 \mathrm{~mm}$ 厚の軟質ガラス板で ふさがれている。蒸発室のトレイには、一辺が $3 \mathrm{~cm}$ の字アングルを使用し、これを $6 \mathrm{~cm}$ 間隔で 13 段配置した。トレイの上には、波状にウィック材 が敷いてある。ウィック材には吸水性、蒸発性に 優れた新素材である黒色のソーラ $\alpha$ (ユニチカ製) ${ }^{3}$ を使用した。箱の下部には、凝縮室が設けてあ る。凝縮室の底は外部との熱交換をよくするため に $3 \mathrm{~mm}$ 厚アルミ板で作ってある。上側面には、塩 水タンクから塩水を供給するための穴が流量計を 介して設けてあり、また下側面にはガラス面から の凝縮水、濃縮塩水、凝縮室からの凝縮水を取り 出すための3個の穴が開けてある。また各部分の 温度を測定するために、図中 $\mathrm{T}_{1} \sim \mathrm{T}_{6}$ の位置に $\mathrm{K}$ 夕 イプ熱電対を設置した。

性能測定はすべて、ソーラシミュレータの下で 行われた。海水の代わりに $3.5 \mathrm{wt} \%$ の食塩水を一定 量流し、得られる蒸留水収量、塩水出口流量、濃 度変動、温度変動を記録した。照射強度に関して は、一定の強度で4時間照射、1時間冷却した場合 と、春分・秋分の日を模擬した場合について行っ た。一定照射の場合、蒸留水が出始めた時点を $\mathrm{t}=0$ とした。

\section{RESULTS AND DISCUSSION}

蒸留器内各位置における温度変動の測定例を Fig.2に示す。(a)は照射強度 $\mathrm{I}=300 \mathrm{~W} / \mathrm{m}^{2}$ 、塩水流量

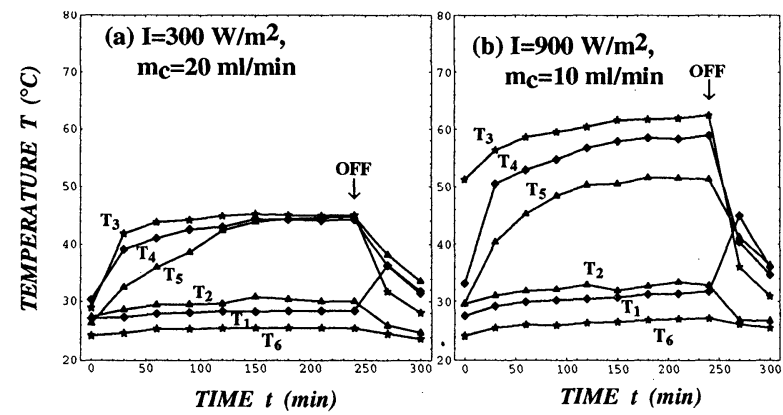

FIG.2.Comparison of the temperature variations between two cases of I. $\mathrm{m}_{\mathrm{c}}=20 \mathrm{ml} / \mathrm{min}$ の場合であり、(b)は $\mathrm{I}=900 \mathrm{~W} / \mathrm{m}^{2} 、$ $\mathrm{m}_{\mathrm{c}}=10 \mathrm{ml} / \mathrm{min}$ の場合である。いずれの場合も、そ のIにおける最大の蒸留効率を記録した場合を示し てある。(b)の場合には、ガラス内側の温度は $60^{\circ} \mathrm{C}$ 以上に達していることがわかる。

それぞれの場合の蒸留水収量の変化の様子を示 したのがFig.3である。各図は3本の曲線からなる が、一番下側は下部凝縮室からの収量、次が上部 ガラス面から、一番上の曲線はそれらの合計を表 している。凝縮室からの寄与はどちらも数\%と非 常に小さく、その効果を高めるための工夫が必要 であることを示している。

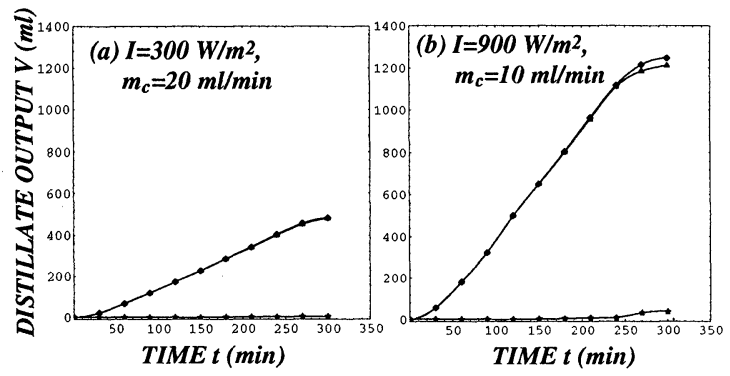

FIG.3.Variation of the distillate output at $\mathrm{I}=300$ (a) and 900 (b) W/m².

蒸留収量は供給する塩水の流量に依存すること が予想される。すなわち、塩水流量があまりに少 なければ、収量は殆どないであろうし、また逆に あまり多いと水温は上昇せず、従って蒸発量は少 なくなり収量はあまり多くはならないであろう。 すなわち、このことは収量が最大となる最適塩水 流量の存在を示唆する。このような見通しのもと に蒸留収量の塩水流量依存性に関する測定を行っ

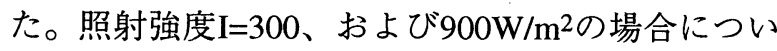
ての結果をFig.4に示す。

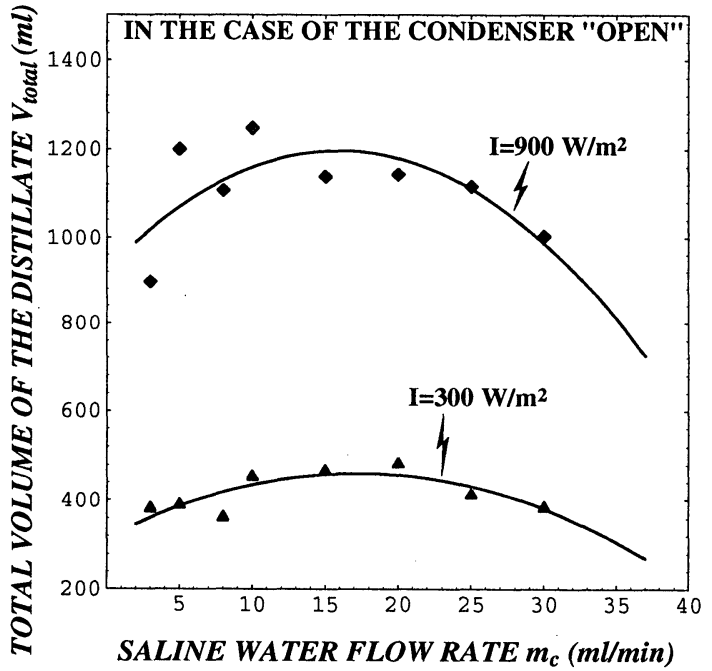

FIG.4.Dependence of the total volume of the distillate on the saline water flow rate. 
図中の実線はひとつの試みとして放物線に最小 自乗フィットさせた結果であり、どちらの場合も 約 $15 \mathrm{ml} / \mathrm{min}$ で収量は最大となることが解る。この 值は蒸発面積 $1 \mathrm{~m}^{2}$ 当り約 $30 \mathrm{ml} / \mathrm{min} に$ 相当する。ま た、この流量の時、塩水出口濃度はそれぞれ約

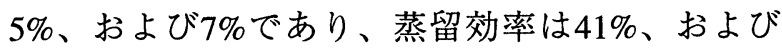
35\%である。

さて、この最適流量の場合について、収量の照 射強度依存性に関する測定を行った。その結果を Fig.5に示す。

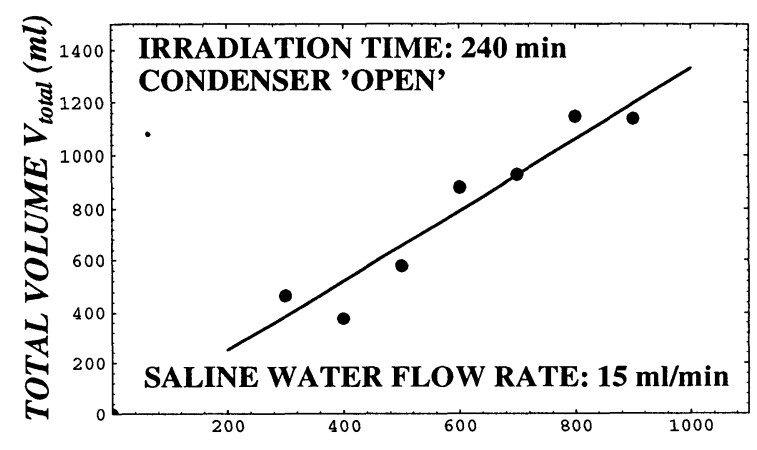

IRRADIATION INTENSITY I (W/m²)

FIG.5.Dependence of the total volume on the irradiation intensity.

これから蒸留収量は照射強度に正比例している ことが解る。従って、最適流量も照射強度には依 存しないものと予想される。

春分・秋分の日の模擬実験結果については別の 機会に報告する予定である。また、ここで示した
結果は野外測定の際の最適条件を決定するための 基礎デー夕を得るためのものであることを打断り しておきたい。さらにここでは新型の太陽熱蒸留 器についての結果のみ示し、その結果を他の方式 のものと比較はしていない。しかし、われわれは 同じ集光面積を持つ他の方式の蒸留器についても 測定を行っており、収量においても効率において も本方式が優れていることは確かめてある。

\section{SUMMARY}

傾斜トレイ型とウィック型の特長を兼ね備え、 かつ凝縮室を別に設けた「凝縮室付き傾斜卜レ イ、ウィック型太陽熱蒸留器」を製作し、その室 内性能試験を行った。ウィック材には、ユニチカ

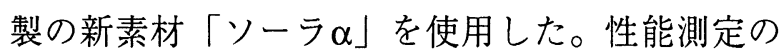
結果、(1)蒸留収量は照射強度に正比例して増加す ること、(2)最適塩水流量が存在し、かつ(3)その值 は照射強度には依らないことが分かった。しか し、凝縮室の効果は不十分であり、設計に改善の 余地があることが指摘された。

\section{REFERENCES}

${ }^{1}$ Suda, F: Renewable Energy, edit. by Sayigh (Pergamon, 1992) 2, 1162-1166.

${ }^{2}$ Japan Solar Energy Society: Solar Energy Utilization Handbook (1985) Chap.10.

${ }^{3}$ Furuta, T: SEN-I GAKKAI 45134 (1989).

'95 SAS Intelligent Symposium 